\title{
A Twin Study of the Genetic Influences on the Electroencephalogram
}

\author{
J. P. R. YOUNG,* M. H. LADER, $†$ and G. W. FENTON $\ddagger$
}

Many attempts have been made to relate individual differences in the background electroencephalogram (EEG) to various psychiatric conditions (Glaser, 1963; Hill, 1963; W'ilson, 1965) and equivalent investigations have recently been carried out with the averaged evoked response waveform (Shagass and Schwartz, 1961, 1962, 1963, and 1965; Jones et al, 1965; Callaway, Jones, and Donchin, 1970) and the alpha attenuation response (Blum, 1957; Wells and Wolf, 1960; Davidoff and McDonald, 1964; Milstein, Stevens, and Sachdev, 1969). The last two measures represent changes induced in the EEG by stimulation.

The main features of the spontaneous EEG show marked between subject variability but a tendency towards consistency and long-term stability within the same individual (Hill, 1963). Similar characteristics have been described for the averaged evoked response waveform (Dustman and Beck, 1963 and 1965) and the alpha attenuation response (Fenton and Scotton, 1967; Milstein et al, 1969). While there is strong presumptive evidence that the interindividual differences in the background EEG are influenced by genetic factors, the exact role of heredity remains unknown (Clarke and Harding, 1969). There have been no previous systematic investigations of the genetic aspects of the alpha attenuation response, but the contribution of heredity to the individual variation in the averaged evoked response is claimed to be substantial (Dustman and Beck, 1965). These findings however remain unconfirmed.

In the present study, standardized EEG recordings were obtained from 64 well matched, identical and fraternal twins and measures made of the spontaneous EEG and the alpha attenuation and the averaged evoked responses. By this means, the genetic component of variation of the spontaneous

Received 30 April 1971.

* The Bethlem Royal and Maudsley Hospital.

† Member of External Scientific Staff, Medical Research Council, Institute of Psychiatry, London SE5.

‡ Institute of Psychiatry, The Bethlem Royal and Maudsley Hospital.
EEG and its responses to stimulation could be estimated.

\section{Methods}

Subjects. As the spontaneous EEG (Hill, 1963), the AAR (Milstein et al, 1969) and the averaged evoked response (Dustman and Beck, 1965) vary with age during childhood and adolescence, and as advancing age and acquired organic brain disease affect these measures, the age range of the subjects was limited to 19-40. As menstruation also affects the EEG (Margerison, Anderson, and Dawson, 1964), the study was confined to males, all of whom were medically and psychiatrically healthy.

The total series comprised 17 pairs of identical twins (mean age 28 years) and 15 pairs of fraternal twins (mean age 27 years). Zygosity was established by blood grouping of 9 systems (ABO, MNS, P, Rhesus, Lutheran, Kell, Lewis, Duffy, and Xga) so that the chance of misclassifying a fraternal pair as identical would be less than 0.05 (Smith and Penrose, 1955).

Procedure. Both twins in each pair were investigated on the same day at approximately the same time under identical experimental conditions. The subject was comfortably seated alone in a small semi-darkened and sound protected room, the recording apparatus being in an adjacent laboratory.

For measurement of the alpha index, the mean alpha amplitude and the alpha attenuation response, the EEG derived from right sided bipolar electrodes-F4 and P4 in the 10/20 system-was recorded on an Offner Type $T$ electroencephalograph. The alpha index was defined as the percentage of recording time during which waves within the alpha frequency band $(8-13 \mathrm{~Hz})$ and of amplitude of not less than $15 \mu \mathrm{V}$ were present, and the mean alpha amplitude as the average of the peak-to-peak amplitudes of all such waves. Both variables were measured manually from the tracing of the last minute of a 5-minute recording period during which the subject relaxed quietly with his eyes closed. The test-retest reliability of both these measures has been reported at +0.91 (Fenton and Scotton, 1967).

The method used for measurement of the alpha attenuation response resembled that described by Fenton and Scotton (1967) and Young and Fenton (1971). Sixty consecutive paired flash stimuli ( $70 \mathrm{msec}$ delay) were presented at irregular intervals $(5-30 \mathrm{sec})$ using an 
SLE Mark III stroboscope with the light source $25 \mathrm{~cm}$ in front of the subject's closed eyes. Each stimulus was delivered only when a prominent alpha rhythm was seen on the EEG tracing. A progressive decrement in the duration of successive alpha attenuation responses was noted during the first 25 stimulus trials but, with further stimulation, the response altered little. The mean response duration for the first 25 stimulus presentations (R1-25) was therefore taken as an index of the prehabituation level and that for the subsequent 35 stimulus trials (R26-60) as an index of the posthabituation level. The mean value for the total stimulus series $(R 1-60)$ was also determined.

With each subject, averaged evoked cerebral potentials were recorded to a series of standardized auditory click stimuli of moderate intensity presented at irregular intervals (8-12 sec) through a loudspeaker behind the subject's chair. The amplified EEG derived from midline electrodes $(\mathrm{Cz}-\mathrm{Pz})$ was recorded on analogue tape and the averaged evoked response was later computed off-line using a small special purpose digital computer (Biomac 500). The averaged waveforms were then subjected to a fully automatic computer analysis in which a product moment correlation was calculated between one response and the corresponding evoked response of the subject's co-twin. With each response, two separate analyses were performed: (1) over the latency range $20-300 \mathrm{~m} \mathrm{sec}$ and (2) over the latency range $20-498$ msec.

The analogue tape recordings of the background EEG obtained during the auditory stimulation procedure were also analysed through 4 parallel band-pass filters with half-amplitude frequency ranges of 2.3-4.0, 4.0-7.5, $7 \cdot 5-13 \cdot 5$, and $13 \cdot 5-26.0 \mathrm{~Hz}$, respectively. For each subject, 645 -second epochs were averaged and the mean rectified voltage obtained for each waveband. By addition, the total mean rectified voltage $(2 \cdot 3-26 \cdot 0 \mathrm{~Hz})$ was also determined.

\section{Results}

Mean within-twin-pair differences for each of the EEG and alpha attenuation response variables were expressed as intraclass correlation coefficients. The correlations obtained together with the product moment correlations for the two averaged evoked response measures were then compared between the two twin series and between each of these and a further constructed series of unrelated subjects. Thus, by pairing age-matched individual identical and fraternal twins, a third, non-twin (NT) series was formed in which the subjects in each pair were genetically unrelated. If the variables recorded are strongly influenced by genetic factors, not only should the identical twin (MZ) correlations be higher than those in the fraternal twin series (DZ), but in both twin series the values obtained should be in excess of those in the third series. The significance of the difference between corresponding correlations for the three subject groups was estimated by the standard $\mathrm{z}$-transformation procedure and a one-tailed test of significance.

In Table I, the intraclass correlation coefficients are listed for the three subject series for each of the EEG and alpha attenuation response variables. Mean product moment correlations for the two averaged evoked response measures are also given. The latter were computed by averaging the correlation coefficients (after $z$-transformation) for all twin pairs in each of the subject groups.

\section{TABLE I}

COMPARISON OF CORRELATION COEFFICIENTS FOR EEG VARIABLES MEASURED IN THE THREE SUBJECT SERIES

\begin{tabular}{|c|c|c|c|}
\hline & $\mathrm{rMZ}$ & $\mathrm{rDZ}$ & rNT \\
\hline No. of pairs & 17 & 15 & 30 \\
\hline $\begin{array}{l}\text { Spontaneous EEG variables } \\
\text { Alpha index } \\
\text { Mean alpha aplitude } \\
\text { Broad band frequency analysis } \\
2 \cdot 3-4 \cdot 0 \mathrm{~Hz} \\
4 \cdot 0-7 \cdot 5 \mathrm{~Hz} \\
7 \cdot 5-13 \cdot 5 \mathrm{~Hz} \\
13 \cdot 5-26 \cdot 0 \mathrm{~Hz} \\
2 \cdot 3-26 \cdot 0 \mathrm{~Hz} \text { (Total) }\end{array}$ & $\begin{array}{l}+0.51 \dagger \\
+0.42^{*} \\
+0.24 \\
+0.66 \mathrm{~g} \\
+0.52 \dagger \\
+0.90 \mathrm{~g} \\
+0.64^{*}\end{array}$ & $\begin{array}{l}+0.16 \\
+0.31 \\
+0.31 \\
+0.34 \\
+0.29 \\
+0.56 t \\
+0.35\end{array}$ & $\begin{array}{l}-0.02 \\
-0.13 \\
\\
+0.34 \\
+0.07 \\
-0.02 \\
+0.05 \\
+0.11\end{array}$ \\
\hline $\begin{array}{l}\text { Alpha attenuation response varia } \\
\mathrm{R} 1-25 \\
\mathrm{R} 26-60 \\
\mathrm{R} 1-60\end{array}$ & $\begin{array}{l}\text { les } \\
+0.46^{*} \\
+0.62^{\star *} \\
+0.58 \ddagger\end{array}$ & $\begin{array}{l}+0.17 \\
+0.21 \\
+0.30\end{array}$ & $\begin{array}{l}-0.24 \\
-0.18 \\
-0.19\end{array}$ \\
\hline $\begin{array}{l}\text { Averaged evoked response variabl } \\
\text { Latency } 20-300 \mathrm{~m} \text { sec } \\
\text { Latency } 20-498 \mathrm{~m} \mathrm{sec}\end{array}$ & $\begin{array}{l}\text { es } \\
+0.719 \\
+0.76 \mathrm{~g}\end{array}$ & $\begin{array}{l}+0.39 \\
+0.55 t\end{array}$ & $\begin{array}{l}+0.07 \\
+0.40^{*}\end{array}$ \\
\hline
\end{tabular}

${ }^{*} \mathrm{p}<0.05 ;+\mathrm{p}<0.02 ; \neq \mathrm{p}<0.01 ; * * \mathrm{p}<0.005 ; 9 \mathrm{p}<0.001$.

It can be seen that in terms of the spontaneous EEG, significant correlations are obtained in the identical twin series for 6 of the 7 variables measured whereas in the two other subject groups, only one of the 14 correlations reach significance. Exactly the same pattern is evident in the results obtained for the variables of the alpha attenuation and averaged evoked responses. In each instance, the identical twin correlations are higher than those in the fraternal twin series and in both twin series, the values obtained are in excess of those in the unrelated subject group. The significance of the differences between the respective correlations in the three subject series is shown in Table II.

Although the differences between corresponding correlations reach significance in only one instance in the $M Z-D Z$ comparisons and in two instances in the DZ-NT comparisons, 10 of the 11 correlations in the identical twin series are significantly higher than the corresponding values in the genetically unrelated subject series. 
Similar results were thus obtained for the measures of the spontaneous EEG and for the changes induced in the background activity by stimulation procedures.

\section{TABLE II}

SD BETWEEN CORRESPONDING CORRELATIONS IN THREE SUBJECT SERIES FOR THE DIFFERENT EEG VARIABLES MEASURED

\begin{tabular}{|c|c|c|c|}
\hline & $\mathrm{rMZ}-\mathrm{rDZ}$ & $r M Z-r N T$ & $\mathrm{rDZ}-\mathrm{rNT}$ \\
\hline $\begin{array}{l}\text { Spontaneous EEG variables } \\
\text { Alpha index } \\
\text { Mean alpha amplitude } \\
\text { Broad band frequency analysis } \\
2 \cdot 3-4.0 \mathrm{~Hz} \\
4 \cdot 0-7.5 \mathrm{~Hz} \\
7.5-13.5 \mathrm{~Hz} \\
13.5-26.0 \mathrm{~Hz} \\
2.3-26.0 \mathrm{~Hz} \text { (Total) }\end{array}$ & $\begin{array}{c}\text { NS } \\
\text { NS } \\
\text { NS } \\
\text { NS } \\
\text { NS } \\
\text { p } 0.02 \\
\text { NS }\end{array}$ & \begin{aligned} $\mathrm{p}< & <0.05 \\
\mathrm{p} & <0.05 \\
& \multicolumn{1}{c}{$ NS } \\
$\mathrm{p} & <0.02 \\
\mathrm{p} & <0.05 \\
\mathrm{p} & <0.001 \\
\mathrm{p} & <0.05\end{aligned}$ & $\begin{array}{c}\text { NS } \\
\text { NS } \\
\text { NS } \\
\text { NS } \\
\text { NS } \\
\text { p }<0.05 \\
\text { NS }\end{array}$ \\
\hline $\begin{array}{l}\text { Alpha attenuation response varia } \\
\text { R1-25 } \\
\text { R26-60 } \\
\text { R1-60 }\end{array}$ & $\begin{array}{l}\text { bles } \\
\text { NS } \\
\text { NS }\end{array}$ & $\begin{array}{l}\mathrm{p}<0.02 \\
\mathrm{p}<0.002 \\
\mathrm{p}<0.01\end{array}$ & $\underset{p}{\text { NS }}$ \\
\hline $\begin{array}{l}\text { Averaged evoked response variab } \\
\text { Latency } 20-300 \mathrm{msec} \\
\text { Latency } 20-498 \mathrm{msec}\end{array}$ & NS & $\begin{array}{l}\mathrm{p}<0.01 \\
\mathrm{p}<0.05\end{array}$ & $\begin{array}{l}\text { NS } \\
\text { NS }\end{array}$ \\
\hline
\end{tabular}

\section{Discussion}

Although the results of early investigations were conflicting (Loomis, Harvey, and Hobart, 1936; Davis and Davis, 1936; Gottlober, 1938; Raney, 1934; Lennox, Gibbs, and Gibbs, 1945), subsequent twin and family studies have generally confirmed the importance of genetic determinants of the main features of the spontaneous EEG (Vogel, 1958, 1962, and 1966; Dieker, 1967; Zung and Wilson, 1967). Particularly convincing evidence has been provided by the inspection of recordings obtained from elderly identical twins (Heuschert, 1963) and from twins reared apart from an early age (Juel-Nielsen and Harvald, 1958). Nevertheless, controversial issues remain and the precise role of heredity in the genesis of the normal EEG remains unknown.

Clarke and Harding (1969) criticized previous work as being restricted to visual interpretation and simple matching of records and were themselves unable to differentiate identical and fraternal twin pairs when using the same techniques. Furthermore, from automatic frequency analysis data, it was suggested that the within-pair similarity in terms of the harmonic mean frequency (Harding et al, 1966) was only marginally greater in the identical pairs. In contrast, Dumermuth (1968) from an analysis of the variance spectra of 6 identical and 4 fraternal twin pairs described almost identical characteristics in 5 of the monozygotic pairs but pronounced dissimilarities within the fraternal pairs.

In the present study, except for the low frequency $(2 \cdot 3-4.0 \mathrm{~Hz})$ waveband to which movement artefact may have contributed significantly, the same consistent pattern is evident in the results obtained for all the recorded measures of the spontaneous EEG. The genetic component of variation is in addition equally well marked for the duration of the alpha attenuation response induced by photic stimulation and for the averaged evoked response recorded to auditory click stimuli. The latter findings are in keeping with those reported for the visually evoked potential waveform (Dustman and Beck, 1965). Similar results are obtained for both manually and automatically quantified variables, though the identical twin correlations for the former are somewhat smaller, perhaps due to increased measurement error.

While the physiological processes which underlie the EEG, the alpha attenuation response (Moruzzi and Magoun, 1949; Lindsley, 1958; Evarts, 1964), and the averaged evoked response (Creutzfeldt and Kuhnt, 1967) are largely obscure, the present findings indicate that individual differences in the spontaneous EEG and its responses to experimental stimulation are strongly influenced by genetic factors. Since the majority of the limitations and biases to which the twin method is exposed (Neel and Schull, 1954; Clarke and McConnell, 1969; Shields, 1971) tend together with measurement error to reduce the apparent strength of the genetic component of variation for the characteristics investigated, the results obtained probably represent a conservative estimate of the true influence of genetic factors.

\section{Summary}

Electroencephalogram recordings were obtained from 64 young adult male identical and fraternal twins. Measurements were made of the spontaneous EEG and of the alpha attenuation response following serially presented flash stimuli. In each subject, averaged evoked cerebral potentials were recorded to auditory click stimuli. Comparison of the mean within-twin-pair differences for the variables measured indicated that genetic factors are significant determinants of both the background EEG and of changes induced in this by experimental stimulation.

The study was made possible by a generous grant from the Bethlem Royal Hospital and the Maudsley Hospital Research Fund, and general support was provided by the Medical Research Council. 


\section{REFBRENCES}

Blum, R. H. (1957). Alpha rhythm responsiveness in normal, schizophrenic, and brain-damaged persons. Science, 126, 749750.

Callaway, E., Jones, R. T., and Donchin, E. (1970). Auditory evoked potential variability in schizophrenia. Electroencephalography and Clinical Neurophysiology, 29, 421-428.

Clarke, C. A. and McConnell, R. B. (1969). Pitfalls and problems in genetic studies. In Selected Topics in Medical Genetics, pp. 1-21. Ed. by C. A. Clarke, Oxford University Press, London.

Clarke, L. G. and Harding, G. F. A. (1969). Comparisons of monoand dizygotic twins with respect to some features of the electroencephalogram. Proceedings of the Electro-Physiological Technology Association, 16, 94-101.

Creutzfeldt, O. D. and Kuhnt, U. (1967). The visual evoked potential: physiological, developmental and clinical aspects. In The Evoked Potentials, p. 29-41. Ed. by W. Cobb and C. Morocutti, Electroencephalography and Clinical Neurophysiology, Suppl. 26.

Davidoff, R. A. and McDonald, D. G. (1964). Alpha blocking and autonomic responses in neurological patients. Archives of Neurology, 10, 283-292.

Davis, H. and Davis, P. A. (1936). Action potentials of the brain in normal persons and in normal states of cerebral activity. Archives of Neurology and Psychiatry, 36, 1214-1224.

Dieker, H. (1967). Untersuchungen zur Genetik besonders regelmässiger hoher Alpha-Wellen im EEG des Menschen. Humangenetik, 4, 186-216.

Dumermuth, G. (1968). Variance spectra of electroencephalograms in twins. In Clinical Electroencephalography of Children, pp. 119-154. Ed. by P. Kellaway and I. Petersen. Grune and Stratton, New York and London.

Dustman, R. E. and Beck, E. C. (1963). Long-term stability of visually evoked potentials in man. Science, 142, 1480-1481.

Dustman, R. E. and Beck, E. C. (1965). The visually evoked potential in twins. Electroencephalography and Clinical Neurophysiology, 19, 570-575.

Evarts, E. V. (1964). Temporal patterns of discharge of pyramidal tract neurones during sleep and waking in the monkey. Fournal of Neurophysiology, 27, 152-171.

Fenton, G. W. and Scotton, L. (1967). Personality and the alpharhythm. British fournal of Psychiatry, 113, 1283-1289.

Glaser, G. H. (1963). EEG and Behavior. Basic Books Inc, New York.

Gottlober, A. B. (1938). The inheritance of brain potential patterns. fournal of Experimental Psychology, 22, 193-200.

Harding, G., Jeavons, P. M., Jenner, F. A., Drummond, P., Sheridan, M., and Howells, G. W. (1966). The electroencephalogram in three cases of periodic psychosis. Electroencephalography and Clinical Neurophysiology, 21, 59-66.

Heuschert, D. (1963). EEG Untersuchungen an eineiigen Zwillingen im höheren Lebensalter. Zeitschrift für menschliche Verebungs- und Konstitutionslehre, 37, 128-172.

Hill, J. D. N. (1963). The EEG in psychiatry. In Electroencephalography, 2nd ed., chap. XII, pp. 368-428. MacDonald, London.

Jones, R. T., Blacker, K. H., Callaway, E., and Layne, R. S. (1965). The auditory evoked response as a diagnostic and prognostic measure in schizophrenia. American fournal of Psychiatry, 122 33-41.

Juel-Nielsen, N. and Harvald, B. (1958). The electroencephalo- gram in uniovular twins brought up apart. Acta Genetica et Statistica Medica, 8, 57-64.

Lennox, W. G., Gibbs, E. L., and Gibbs, F. A. (1945). The brainwave pattern, an hereditary trait. Fournal of Heredity, 36, 233243.

Lindsley, D. B. (1958). The reticular formation system and perceptual discrimination. In Reticular Formation of the Brain, p. 513-534. Ed. by H. H. Jasper and L. D. Proctor. Little, Brown and Co., Toronto.

Loomis, A. L., Harvey, E. N., and Hobart, G. (1936). Electrical potentials of the human brain. Fournal of Experimental Psychology, 19, 249-279.

Margerison, J. H., Anderson, W. Mc. C., and Dawson, J. (1964). Plasma sodium and the EEG during the menstrual cycle of normal human females. Electroencephalography and Clinical Neurophysiology, 17, 540-544.

Milstein, V., Stevens, J., and Sachdev, K. (1969). Habituation of the alpha attenuation response in children and adults with psychiatric disorders. Electroencephalography and Clinical Neurophysiology, 26, 12-18.

Moruzzi, G. and Magoun, H. W. (1949). Brain stem reticular formation and activation of the EEG. Electroencephalography and Clinical Neurophysiology, 1, 455-473.

Neel, J. V. and Schull, W. J. (1954). In Human Heredity. University of Chicago Press, Chicago.

Raney, E. T. (1934). Brain potentials and lateral dominance in identical twins. Fournal of Experimental Psychology, 24, 21-39.

Shagass, C. and Schwartz, M. (1961). Reactivity cycle of somatosensory cortex in humans with and without psychiatric disorder. Science, 134, 1757-1759.

Shagass, C. and Schwartz, M. (1962). Cerebral cortical reactivity in psychotic depression. Archives of General Psychiatry, 6, 235242.

Shagass, C. and Schwartz, M. (1963). Psychiatric correlates of evoked cerebral cortical potentials. American fournal of Psychiatry, 119, 1055-1061.

Shagass, C. and Schwartz, M. (1965). Age, personality and somatosensory cerebral evoked responses. Science, 148, 1359-1361.

Shields, J. (1971). Heredity and psychological abnormality. In Handbook of Abnormal Psychology. Ed. by H. J. Eysenck, 2nd ed. Pitman Medical, London. (In press.)

Smith, S. M. and Penrose, L. S. (1955). Monozygotic and dizygotic twin diagnosis. Annals of Human Genetics, 19, 273-289.

Vogel, F. (1958). Über die Erblichkeit des Normalen Elektroenzephalogramms. Georg Thieme Verlag, Stuttgart.

Vogel, F. (1962). Ergänzende Untersuchungen zur Genetik des menschlichen Niederspannungs EEG. Deutsche Zeitschrift für Nervenheilkunde, 184, 105-111.

Vogel, F. (1966). Zur genetischen Grundlage fronto-prazentrale B-Wellen Gruppen im EEG des Menschen. Humangenetik, 2, 227-237.

Wells, C. E. and Wolf, H. G. (1960). Formation of temporary cerebral connections in normal and brain-damaged subjects. Neurology, 10, 335-340.

Wilson, W. P. (1965). Applications of Electroencephalography in Psychiatry: A Symposium. Duke University, Durham, N.C.

Young, J. P. R. and Fenton, G. W. (1971). An investigation of the genetic aspects of the alpha attenuation response. Psychological Medicine, 1, 365-371.

Zung, W. W. K. and Wilson, W. P. (1967), Sleep and dream patterns in twins: Markov Analysis of a genetic trait. In Recent Advances in Biological Psychiatry. Vol. IX, pp. 119-130. Ed. by J. Wortis. Plenum Press, New York. 